\title{
Frančiška Lipovšek
}

University of Ljubljana

Slovenia

\section{Defining the conceptual structure of from and to}

\author{
Summary
}

From and to differ from other prepositions of movement in two significant respects: they entail point-apprehensibility and leave the actual trajector-landmark arrangement unspecified. The difference is due to the presence of two place-functions in their conceptual structure. The first place-function is the same as the one found in the conceptual structure of at. It triggers a point-like conceptualization and is lexicalized together with the path-function. The second place-function is not specified but can be lexicalized separately. The conceptual structure with two place-functions allows for a second preposition, but can at the same time account for the unacceptability of from at and to at. The paper highlights the vagueness of the traditional definitions of from and to, arguing that what is conceptualized as a point is not the landmark but the place of location.

Key words: prepositions, from, to, conceptual structure, path-function, place-function, landmark, trajector

\section{Opredelitev konceptualne strukture predlogov from in to}

Povzetek

From in to se od ostalih predlogov za izražanje premikanja razlikujeta v dveh bistvenih pogledih: implicirata točkovno konceptualizacijo in ne specificirata prostorskega razmerja med trajektorjem in orientacijsko točko. Omenjena razlika je posledica prisotnosti dveh funkcij lokacije v njuni konceptualni strukturi. Prva je enaka funkciji lokacije v konceptualni strukturi predloga at. Sproži točkovno konceptualizacijo in je leksikalizirana skupaj s funkcijo poti. Druga funkcija lokacije ni specificirana, lahko pa je leksikalizirana ločeno. Konceptualna struktura z dvema funkcijama lokacije omogoča rabo dodatnega predloga, vendar lahko še vedno utemelji nesprejemljivost kombinacij from at in to at. Članek med drugim izpostavi nenatančnost tradicionalnih definicij predlogov from in to $\mathrm{z}$ vidika konceptualizacije: predmet točkovne konceptualizacije namreč ni orientacijska točka, temveč mesto lokacije.

Ključne besede: predlogi, from, to, konceptualna struktura, funkcija poti, funkcija lokacije, orientacijska točka, trajektor 


\section{Defining the conceptual structure of from and to}

\section{Introduction}

Spatial prepositions express static and dynamic relations that can be described schematically as geometric configurations between a TRAJECTOR (TR) and a LANDMARK (LM): the former is the primary focus and the carrier of the relation, and the latter a secondary focal participant viewed as the reference point for locating the TR (Langacker 1987, 217, 231-243; 2000, 171-174, 2008, 113). If movement is involved, the TR moves through a spatial trajectory determined by a specific relationship with the LM.

From and to belong to the spatial prepositions that express movement along a bounded path. The conceptualization involves not only a dynamic scene, with the TR moving away from or towards the LM, but also a static scene describing a specific TR-LM arrangement at the beginning or end of the path (for example, out of evokes the image of the TR located inside the LM). From and to are exceptions in this respect: they (i) remain vague about the actual TR-LM arrangement and (ii) evoke the image of the LM as a "point or blob" (Lindstromberg 2010, 31). It can be assumed that the reason lies in different conceptual structures. The aim of the paper is to identify the component(s) responsible for the two differences and propose a structure that accounts for both.

The paper is organized as follows. Section 1 discusses the role and lexicalization of functions in the conceptual structure of lative prepositions and identifies the problem of from and to in this respect. Section 2 focuses on the place-function AT and its lexicalization. Section 3 examines the occurrence of from at and to at to argue for a conceptual structure with two place-functions. A short discussion follows in section 4 . The main points are summed up in the Conclusion.

\section{Towards the conceptual structure of from and to}

Arguing that "semantic structure is conceptual structure" (cf. also Heine 1997, Talmy 1983), Jackendoff (1983) refers to prepositions as FUNCTIONS and uses the following notations to represent their conceptual structure:

(1)

a. [Place PLACE-FUNCTION ([Thing THING])]

b. [Path PATH-FUNCTION ([Place PLACE-FUNCTION ([Thing THING])])]

For example:

(2)

a. The cat was hiding in the basket.

[Place IN ([Thing BASKET])]

b. The cat jumped out of the basket.

[Path FROM ([Place IN ([Thing BASKET])])]

c. The cat jumped into the basket.

[Path TO ([Place IN ([Thing BASKET])])]

The preposition in in (2a) is the lexicalization of the place-function IN, which involves the conceptualization of the LM as some kind of container. In (2b) and (2c), the conceptual structure 
of the preposition consists of a path-function (with FROM standing for the source-path-function and TO for the goal-path-function) and the place-function IN. The two functions are lexicalized together as out of and into, respectively.

Some prepositions express place- as well as path-functions. In the locative use, the conceptual structure of the preposition consists of a place function only; in the lative ${ }^{1}$ use, its conceptual structure consists of a path-function and a place-function. For example:

(3)

a. The child was hiding in the closet/under the bed/behind the tree.

[Place IN/UNDER/BEHIND ([Thing CLOSET/BED/TREE])]

b. The child hid in the closet/under the bed/behind the tree.

[Path TO ([Place IN/UNDER/BEHIND ([Thing CLOSET/BED/TREE])])]

By contrast to locative-allative prepositions (i.e., those used for locations as well as goal-paths), locative-ablative prepositions (i.e., those used for locations as well as source-paths) are few in number. In fact, there are only two true representatives of the kind: off and out of. Furthermore, their primary function is not locative but ablative: ${ }^{2}$

a. The glider lifted off the ground.

[Path FROM ([Place ON ([Thing GROUND])])]

b. The plane's nose is already off the ground.

[Place OFF ([Thing GROUND])]

c. They drove out of town.

[Path FROM ([Place IN ([Thing TOWN])])]

d. They're out of town.

[Place OUT OF ([Thing TOWN])]

In their lative uses, the prepositions in (2-4) above share one significant property: their conceptual structure consists of a path-function and a place-function, which are lexicalized together as one lexical item. The two functions can also be lexicalized separately:

(5) The cat ran from under the sofa.

[Path FROM ([Place UNDER ([Thing SOFA])])]

In example (5), the path-function is lexicalized as from, and the place-function as under. As pointed out by Keizer (2008), from combines with another preposition if the latter expresses a TR-LM relationship that differs from the expected, default one (as implied by the semantics of the TR and LM). For illustration (adapted from Lipovšek 2013):

(6)

a. I heard an angry voice coming from under the table/behind the closet/above the balcony.

b. ${ }^{*}$ I heard an angry voice coming from at their table/in the closet/on the balcony.

Used throughout the paper as the cover term for the ablative use (i.e. with the TR moving in a direction away from the LM) and the allative use (i.e. with the TR moving in a direction towards the LM).

2 Perhaps a more appropriate designation would be ablative-locative. 
It appears that the lexicalization of each function separately occurs only with source-paths. With goal-paths, prepositions are used that can lexicalize both functions together:

a. All of a sudden, the cat jumped on/under/behind the sofa.

b. *All of a sudden, the cat jumped to on/under/behind the sofa.

By contrast to from, to is not normally followed by another preposition, irrespective of the TR-LM relationship. Moreover, from wihout the second preposition entails a default relationship, while to does nothing of the kind: if the apple in (8a) was most certainly IN the bag, the ball in (8b) did not end IN the hole:

(8)

a. The apple rolled from the bag.

b. The (golf) ball (bounced off the ground and) rolled to the hole.

The LM in (8a) is conceived of as a container, while the conceptualization of (8b) involves the LM as the endpoint of the TR's path, with the TR located within the LM's range. This difference suggests the following conceptual structures in (8):

(9)

a. [Path FROM ([Place IN ([Thing BAG])])]

b. [Path TO ([Thing HOLE)])]

Notation (9a) implies that the path-function FROM and the place-function IN are lexicalized together as from. In other words, it implies that the conceptualization of the LM in (8a) as a container is evoked by from. The problem of this implication is that it makes from polysemic. Compare:

(10) The apple rolled from the table.

[Path FROM ([Place ON ([Thing TABLE])])]

Polysemy would suggest that the conceptual structures of from in (8a) and from in (10) contain the same place-functions as out of and off, respectively. ${ }^{3}$ Nevertheless, the actual TR-LM arrangement is not contained in the meaning of from but must be derived from the semantics of the TR and LM and the context. The conceptual structure of from remains the same irrespective of the actual TR-LM arrangement:

\section{(11) [Path FROM ([Place PLACE-FUNCTION ([Thing THING])])]}

The source-path-function is lexicalized as from, while the place-function is lexicalized only if the TR-LM relationship differs from the expected one. If the place function is lexicalized, the TR-LM arrangement is implied by the conceptual structure of the second preposition. If the place-function is not lexicalized, the TR-LM arrangement is derived from the semantics of the TR and LM. The place-function in $(12 \mathrm{~b}-\mathrm{c})$ is printed in italics ${ }^{4}$ to indicate that the specification of the TR-LM arrangement is not part of the conceptual structure of from.

For their possible interchangeability, see Lipovšek 2013.

Proposed by the author for the sake of clarity. 
(12)

a. The ball rolled from under the table.

[Path FROM ([Place UNDER ([Thing TABLE])])]

b. The apple rolled from the table.

[Path FROM ([Place ON ([Thing TABLE])])]

c. The apple rolled from the bag.

[Path FROM ([Place IN ([Thing BAG])])]

With $t o$, the place-function is not normally lexicalized. We used notation (9b) to illustrate the conceptual structure of to in (8b) above, repeated below as (13):

(13) The ball rolled to the hole.

[Path TO ([Thing HOLE)])]

The most likely interpretation of (13) is that the ball ended right on the edge of the hole, which means that the TR is located within the LM's range. This proximity relationship may turn into coincidence, especially if viewed from afar or if the path is foregrounded. That could explain the missing place-function in the notation under $(13)$. Indeed, Jackendoff $(1983,163)$ states that the internal structure of lative prepositions often consists of a path-function and a reference OBJECT, as in to the floor. He continues by pointing out that the path-function can alternatively be followed by a reference PLACE, as in from under the table. He also states that the "path-function TO tends to combine with place-functions into a single lexical item" (ibid., 165), which suggests not only that the conceptualization of to involves a place-function, but also that the place-function and the path-function are lexicalized together.

The presence of the place-function in the conceptual structure of to becomes evident in cases where the LM clearly keeps its dimensionality. Nevertheless, it cannot be considered lexicalized because the specification of the TR-LM arrangement is not part of the semantics of to:

a. The cat jumped to the windowsill.

[Path TO ([Place ON ([Thing WINDOWSILL])])]

b. I'm going to the kitchen to make some coffee.

[Path TO ([Place IN ([Thing KITCHEN])])]

The recognition of the place-function with to calls for a revision of (13) above. With the LM conceptualized as a point on a line and the TR located in proximity to that point, the placefunction is best represented by AT:

(15) The ball rolled to the hole.

[Path TO ([Place AT ([Thing HOLE])])]

The point-apprehensibility of the LM is the key component of at. As stated by Huddleston and Pullum $(2002,654)$, the "core lexical meaning of at expresses location in a specific geographical position conceived as a point in the plane." From and to are traditionally viewed as dynamic counterparts of at. The conceptualization of the goal-path involves not only a dynamic scene with the TR traversing the path but also a static scene, with the TR located at the endpoint of 
the path. Similarly, the conceptualization of the source-path involves a dynamic scene as well as a static scene, with the TR located at the beginning of the path. The use of from ... to, for example, foregrounds the path and evokes the image of a line between two points:

(16) We swam from one end of the pool to the other.

[Path FROM ([Place AT ([Thing POOL END $])])]+[$ Path TO ([Place AT ([Thing POOL END])])]

Example (16) suggests that the point-like conceptualization of the LM is evoked by from and to and that their conceptual structures contain the place-function AT:

a. [Path FROM ([Place AT ([Thing THING])])]

b. [Path TO ([Place AT ([Thing THING $])])]$

Nevertheless, the notations in (17) are not unproblematic. The inclusion of AT in the conceptual structure of each preposition is in perfect accordance with the view that when from or to is used, the LM's dimensionality and physical properties are largely ignored (cf. Lindstromberg 2010, 31, 44); however, the question arises whether from and to actually ENTAIL point-apprehensibility. Cienki (1989, 134), for example, argues that to cannot be a "motional counterpart" of at. He points out that Tom pushed Bill to the ground does not entail that Bill is AT the ground. Another argument he provides is that humans as LMs readily combine with to (e.g., Simon went home to his wife) but not with at (e.g., ${ }^{*}$ He was at Fred), the reason being that humans are not point-apprehensible. He argues for a very general meaning of to without any further specification of the place function. This line of reasoning can be extended to from: the sentence Peter fell from the tree does not entail that Peter was AT the tree. The notations in (17) should be revised accordingly:

a. [Path FROM ([Place PLACE-FUNCTION ([Thing THING])])]

b. [Path TO ([Place PLACE-FUNCTION ([Thing THING])])]

The presence of the place-function in the structure of from is evident from cases where it is lexicalized separately (e.g., He crawled from under the table). With to, by contrast, the place-function is not normally lexicalized. Instead, a preposition that lexicalizes both functions together is used (e.g., He jumped into the pool / climbed behind the sofa / hid under the table). Nevertheless, actual usage shows that to is occasionally followed by a preposition as well. The following examples are taken from the BNC:

a. His dark eyes directed to beyond the window where the Expo lights sparkled colourfully into the distance.

b. An elderly woman does not want to take the risk, hastily glances at the sharp blades of the door, retreats back to behind the faded white line and waits for the next train.

c. It was a stretched Telecaster, using the same slab ash body with no contouring whatsoever, while its elongated top horn extended to above the twelfth fret and offered good balance for an instrument of its considerable weight. 
d. A scar ran from the corner of his eye to under his jawbone, and his tattooed arms rested on the desk in front of him, which was covered with mementoes of his Legion career.

e. And then his hand moved to under her chin.

As can be inferred from the above sentences, a second preposition may be needed to specify the location of the TR with regard to the LM. There is a difference, for example, between reaching a point and reaching beyond that point. Alternatively, to may be needed to avoid misinterpreting the allative use as locative (cf. (19e)). With the second preposition lexicalizing a function of its own, this usage confirms the presence of the place-function in the conceptual structure of $t o$.

One fact is indisputable: the conceptual structures of from and to contain a place-function that can be lexicalized. The key question is whether this function can be AT.

\section{The place-function AT in the conceptual structure of from and to}

The function of AT can best be explained by looking at its typical lexicalization, the preposition at. Lindstromberg (2010, 173-182) describes spatial at as imprecise about the TR-LM relationship, vague about possible physical contact between the two entities and neutral about their relative sizes. Keizer (2008) observes that, despite its vagueness, at has a narrower range of application than other prepositions, concluding that at must have a specific meaning of its own, namely, expressing location at some non-dimensional, geometric point in space. The point-like conceptualization of the LM and its indefiniteness regarding the exact TR-LM relationship make at unique not only among English prepositions but also crosslinguistically. In the title of his paper, Cuyckens (1984) refers to at as "a typically English preposition", while Cienki $(1989,128)$ comments on that, suggesting that an even more appropriate designation would be "a peculiarly English preposition" because it has no direct equivalent in other languages.

The point-apprehensibility entailed by at does not mean that the TR is necessarily COINCIDENT with the LM. According to Cuyckens (1984), the TR must be included in the REGION of the LM, which covers the area taken by the LM itself as well as the surrounding area outside the LM. It follows that the TR-LM relationship can be that of coincidence or that of proximity. Cuyckens argues that coincidence and proximity are not part of the semantics of at, but rather further specifications that are derived from the semantics of the sentence and the context. Coventry $(2003,255-6)$ states that the use and comprehension of at depends on the relative distance between objects and their possible interaction. Cienki $(1989,104)$ proposes a centrality condition that is based on the relative distance between the TR and the LM: the applicability of at decreases with distance because the TR should not move out of the LM's region. Furthermore, their distance from the observer also plays a role: the relationship may be that of proximity from a close-up view but will turn into coincidence from a more remote point of view because from a distance the whole LM region tends towards a point-like conceptualization. In other words, the TR and the LM will merge into a single point owing to the "mental act of 'zooming out" (Lindstromberg 2010, 173).

If at evokes the picture of a zero-dimensional LM, its conceptual structure consists of a placefunction that takes a point-like argument. This does not imply that the LM is actually a point but rather that it is APPREHENDED as a point, irrespective of its dimensions: 
As counterparts of at, the prepositions from and to should lexicalize the same place-function (together with the path-function):

\section{a. [Path FROM ([Place AT ([Thing POINT])])] \\ b. [Path TO ([Place AT ([Thing POINT])])]}

If from and to are used alone, the notations in (21) seem perfectly plausible. The path-function and the place-function are lexicalized together: FROM and AT as from, and TO and AT as to:

(22) We swam from one end of the pool to the other. (=16)

[Path FROM ([Place AT ([Thing POINT: POOL END])])]

[Path TO ([Place AT ([Thing POINT: POOL END])])]

(23) The apple rolled from the table. $(=10)$

[Path FROM ([Place AT ([Thing POINT: TABLE])]) $]^{5}$

A problem arises when a second preposition follows:

(24) He crawled from under the table.

If we want to apply notation (21a) to (24), it looks as if the place-function AT was either lexicalized as under (25a) or supplanted by the place-function UNDER (25b):

\section{a. ? [Path FROM ([Place AT ([Thing POINT: TABLE])])] \\ b. ? [Path FROM ([Place UNDER ([Thing TABLE])])]}

Both are problematic: (25a) implies that from lexicalizes only the path-function and that the placefunction AT can be lexicalized by prepositions other than at; (25b) implies that the place-function AT and its point-like argument are not part of the structure.

What, on the other hand, speaks in favour of (21) is the unacceptability of from at and to at: the place-function AT cannot be lexicalized as at because it is already lexicalized together with the path function as from or to. To put it simply, at is redundant because the point-like conceptualization is already entailed by from or to. The reasoning behind this argument, however, is challenged by the fact that combinations with at are not, in fact, non-existent. Keizer (2008), for example, provides several examples with from at, pointing out that although from and at are both grammatical prepositions and as such mutually exclusive, ${ }^{6}$ the combination from at may not be entirely unacceptable. This could have important implications for the conceptual structures of from and to. For the purposes of the paper, the occurrence of to at and from at has been checked in the BNC and the $\mathrm{ukWaC}$ and is discussed briefly in the next section.

\footnotetext{
5 The notation differs from that in (10). It implies point-apprehensibility and leaves the actual TR-LM arrangement unspecified.

6 Keizer draws on the theory of Functional Discourse Grammar and the classification of spatial prepositions as proposed by Mackenzie (1992), who distinguishes five grammatical prepositions: at, from, via, to and towards (cited in Keizer 2008).
} 


\section{Arguing for a second place-function}

The corpora search has confirmed the supposed unacceptability of to at. At first sight, the search results might suggest that to at occurs in contexts of sending something to a specific address (referred to by the name of an institution/service, a web page or the noun address). All these occurrences of to at, however, are to be crossed out as insertion mistakes. For example:

a. *Full details of these arrangements are given in Annexes to this paper. General Enquiries on this area should be directed to at SCOTVEC. (BNC)

b. *These CDs can be ordered from Pinecastle at P.O. Box 456, Orlando Florida 32802 or write to at pinecast@inspace.net or http://pinecastle.com. Happy listening! (ukWaC)

c. ${ }^{*}$ Orders for copies of the Licensed Software shall be communicated in writing, by telefax or by telex to at the above address. (BNC)

If to at is practically non-existent, the occurrence of from at ranges from purely spatial uses to temporal ones. As to the former, from at is found mainly with locations implying a part-whole relationship and with the noun home. For example:

a. The presenter, who was Brian Conley, came on at the beginning of the show from at the back of the stage instead of down the stairs and through the audience. ( $\mathrm{ukWaC}$ )

b. New entries are added all of the time, so if you come across a word, acronym or phrase you would like Jargon Busted please let us know via the online contact from at the bottom of this page. (ukWaC)

c. Students can access the project from BOKU or from at home via Internet. (ukWaC)

As to temporal uses, from at occurs mainly with expressions telling the exact time or marking the beginning or end of a time period. For example:

a. We will also celebrate mass in Streatham Court LTE on Thursdays from at $6 \mathrm{pm}$. (ukWaC)

b. Prices of essential foods were controlled from at the start of the war but this often meant subsidy. (ukWaC)

c. Hundreds of pedigree bitches can be kept on the same farm, producing a constant supply of puppies. They are often bred from at a very young age and on a frequent basis. (ukWaC)

It can be concluded that from at is "less unacceptable" than to at. The TR-LM relationship is that of proximity or coincidence (for example, the presenter in (27a) had been waiting AT the back of the stage; the mass in (28a) begins AT 6pm). What is relevant to the discusion is that at now behaves like any other preposition lexicalizing the place-function:

a. He came on from at the back of the stage. (cf. (27a))

[Path FROM ([Place AT ([Thing POINT: BACK-OF-STAGE])])] 
b. He jumped from behind the wall.

[Path FROM ([Place BEHIND ([Thing WALL])])]

Nevertheless, what makes uses like (29a) only marginally acceptable is the requirement that the place-function should not be lexicalized unless the TR-LM relationship differs from the expected, default one. For comparison:

a. He came on from the back of the stage.

[Path FROM ([Place $A T$ ([Thing POINT: BACK-OF-STAGE])])]

b. He jumped from the wall.

[Path FROM ([Place $O N([$ Thing WALL $])])]$

The notations in (29) leave us with the same question as (24) above: How can the second preposition lexicalize the place-function if the latter is already lexicalized together with the path-function? The problem can be solved by recognizing a second place-function in the structure. The following notations are proposed:

a. [Path FROM ([Place AT ([Place POINT: PLACE-FUNCTION ([Thing THING])])])]

b. [Path TO ([Place AT ([Place POINT: PLACE-FUNCTION ([Thing THING])])])]

The first place-function is specified and lexicalized together with the path-function. The specification of the second place-function is not part of the semantics of from and to and can be lexicalized separately by a second preposition. It follows that at in from at (the same would, theoretically, hold for to at) occurs as a lexicalization of this second function.

\section{Discussion}

The notations in (31) are applicable irrespective of whether from and to are used alone or in combination with other prepositions:

a. He came on from the back of the stage. $(=30 \mathrm{a})$

[Path FROM ([Place AT ([Place POINT: AT ([Thing POINT: BACK-OF-STAGE])])])]

b. He jumped from the wall. $(=30 \mathrm{~b})$

[Path FROM ([Place AT ([Place POINT: ON ([Thing WALL])])])]

c. He jumped from behind the wall. $(=29 \mathrm{~b})$

[Path FROM ([Place AT ([Place POINT: BEHIND ([Thing THING])])])]

a. The ball rolled to the hole. $(=15)$

[Path TO ([Place AT ([Place POINT: AT ([Thing POINT: HOLE])])])]

b. The scar ran to under his jawbone. (cf. (19d))

[Path TO ([Place AT ([Place POINT: UNDER ([Thing JAWBONE])])])]

Furthermore, they can account for occasional occurrences of at as the second preposition, but 
at the same time also for its unacceptability: at is precluded not because the place-function AT is already lexicalized but because at as a lexicalization of the SECOND place-function would be redundant or would clash with the intended meaning:

b. *The ball rolled to at the hole. (cf. (33a))

a. ${ }^{*}$ He jumped from at the wall. (cf. (32b))

That at lexicalizes the second place-function is also evident from examples where the lexicalization is required by adverbial modification:

a. Pour the batter from just above the pan. (ukWaC)

b. This procedure is repeated but now the tip of the tongue moves further forward still, to just behind the front teeth, before the ' $\mathrm{i}$ ' is sounded. (ukWaC)

c. I watched his speech from right at the front, among the photographers. (ukWaC)

d. You, with your million citizens in Birmingham and your 40,000 plus employees, delegating responsibility, still had to get the message down even to Handsworth. Can you share with us how that is best achieved, getting the message down to right at the delivery point? $(\mathrm{ukWaC})$

This use, too, is in perfect accordance with the conceptual structures proposed by (31). It confirms not only that the argument of AT is a place of location with its own place-function, but also that the place of location is conceptualized as a point. It occurs with adverbs that typically signal coincidence and, as Mackenzie (1992) puts it, indicate "that the spatial relation holds with more than normal geometrical precision" (quoted in Keizer 2008).

The last observation brings us to the most important part of the discussion. It is crucial to note that what is apprehended as a point is the PLACE OF LOCATION. Cienki (1989), for example, argues that the place-function in the structure of to cannot be specified as AT because to does not entail point-apprehensibility (cf. (18) in section 1). His argument, however, applies to the LANDMARK and the actual TR-LM arrangement, and the two approaches should be kept clearly apart. In (35b) above, for example, it is not the teeth that are conceptualized as a point, but rather the space behind the teeth.

The place of location comprises a multitude of possible locations of the TR with regard to the LM. For example, the place of location in (36) below refers to every single space under the sofa as a possible location. Owing to the place-function AT in the conceptual structure of from, this multitude of possible locations is apprehended as a point:

(36) The cat ran from under the sofa. (= 5)

\section{[Path FROM ([Place AT ([Place POINT: UNDER ([Thing SOFA])])])]}

The point-like conceptualization evoked by from and to should be understood in the following way. The path is conceptualized as a line that begins or ends with a point. That point is the place of location (under the sofa rather than the sofa in (36)). By the mental act of zooming out, however, the place of location can merge with the LM into a single point. 
Last but not least, the notations in (31) apply only to from and to. The conceptual structures of other lative prepositions lack the place-function AT and evoke a conceptualization foregrounding the TR-LM arrangement specified by the second place-function. This difference can be relevant to the choice of the preposition, which depends on "the scale of our mental image" of the LM (Lindstromberg 2010, 31). For example (adapted from Lipovšek 2013):

a. Take the butter from the fridge and cut it into slices.

[Path FROM ([Place AT ([Place POINT: IN ([Thing FRIDGE])])])]

b. Take the butter out of the fridge and wait till it softens.

[Path FROM ([Place IN ([Thing FRIDGE])])]

\section{Conclusion}

What sets from and to apart from other lative prepositions is the conceptual structure with two place-functions, each responsible for one distinctive aspect of their meaning: the first place-function in the structure accounts for the point-apprehensibility, the second one for the vagueness regarding the TR-LM relationship. The second place-function is the same as the one found with other prepositions, but is not specified and can be lexicalized only separately. With other prepositions, this place-function is specified and lexicalized together with the path-function. It is the function that specifies the actual TR-LM arrangement. The first place-function, by contrast, is not found with other prepositions. It is specified as AT and lexicalized together with the path function. It is the same function as the one found in the conceptual structure of at, only that its pointlike argument is the place of location rather than the LM. This appears to clash with traditional definitions; nevertheless, once the path is mentally viewed from a distance, the place of location, the TR and the LM will inevitably merge into a single point.

\section{References}

Cienki, Alan. 1989. Spatial Cognition and the Semantics of Prepositions in English, Polish, and Russian. Munich: Sagner.

Coventry, Kenny. 1998. “Spatial prepositions, functional relations, and lexical specification.” In Representation and Processing of Spatial Relations, edited by Patrick Olivier and Klaus-Peter Gapp, 247-262. Mahwah, NJ: Lawrence Erlbaum.

Cuyckens, Hubert. 1988. "Spatial prepositions in cognitive semantics." In Understanding the Lexicon, edited by Werner Hüllen and Rainer Schulze, 316-328. Tübingen: Max Niemeyer.

Heine, Bernd. 1997. Cognitive Foundations of Grammar. New York: Oxford University Press.

Huddleston, Rodney, and Geoffrey K. Pullum. 2002. The Cambridge Grammar of the English Language. Cambridge: Cambridge University Press.

Jackendoff, Ray. 1983. Semantics and Cognition. Cambridge, Mass.: The MIT Press.

Keizer, Evelien. 2008. "English prepositions in functional discourse grammar." Functions of Language 15 (2): 216-256.

Langacker, Ronald W. 1987. Foundations of Cognitive Grammar, Vol. 1: Theoretical Prerequisites. Stanford: Stanford University Press.

- - - 2000. Grammar and Conceptualization. Berlin and New York: Mouton de Gruyter. 
- - - 2008. Cognitive Grammar: A Basic Introduction. Oxford: Oxford University Press.

Lindstromberg, Seth. 2010. English Prepositions Explained. Revised edition. Amsterdam: Benjamins.

Lipovšek, Frančiška. 2013. "Movement out of, off, and from the landmark: conceptualization of the departure point." Arbeiten aus Anglistik und Amerikanistik (AAA) 38 (2): 187-204.

Mackenzie, J. Lachlan. 1992. „English spatial prepositions in Functional Grammar.“ Working Papers in Functional Grammar 46. Quoted in Keizer, Evelien. 2008. "English prepositions in functional discourse grammar." Functions of Language 15 (2): 216-256.

Talmy, Leonard. 1983. "How language structures space." In Spatial Orientation: Theory, Research and Application, edited by Herbert L. Pick and Linda P. Acredolo, 225-282. New York: Plenum.

\section{Corpora}

BNC: http://www.sketchengine.co.uk

ukWaC: http://www.sketchengine.co.uk 